\title{
Long-Term Use of Risperidone in Children with Disruptive Behavior Disorders and Subaverage Intelligence: Efficacy, Safety, and Tolerability
}

\author{
Magali Reyes, M.D., Ph.D.,1 Jan Croonenberghs, M.D., Ph.D.,2 \\ Ilse Augustyns, Ph.D., ${ }^{3}$ and Marielle Eerdekens, M.D. ${ }^{3}$
}

\begin{abstract}
Objective: The aim of this study was to assess the long-term efficacy and tolerability of risperidone in the treatment of children and adolescents with disruptive behavior disorder (DBD) and below-average intelligence (IQ < 84) over a cumulative period of 2 years.

Methods: We followed 48 patients (6-15 years of age), who had previously completed a 1year open-label study of risperidone, for an additional year of treatment. Efficacy was assessed using the conduct problem subscale of the Nisonger Child Behavior Rating Form (N-CBRF) as a primary outcome measure; other N-CBRF subscales, the Aberrant Behavior Checklist (ABC), and the Clinical Global Impression (CGI) of severity were secondary efficacy measures. Safety and tolerability were also assessed.

Results: Of the 48 patients enrolled in this extension study, 33 (69\%) completed the trial. The efficacy benefits from the original study were maintained over the course of the extension study. Safety and tolerability were good overall, with the number of adverse events (AEs) decreasing in the extension trial, compared to the original trial. Six patients (13\%) discontinued owing to AEs. Weight gain observed in the original trial stabilized during this extension trial. Cognitive testing demonstrated small, but significant, improvements in cognitive ability.

Conclusions: Risperidone is safe and effective in treating DBDs in children over a cumulative period of 2 years.
\end{abstract}

\section{INTRODUCTION}

D ISRUPTIVE BEHAVIOR DISORDERS (DBDs)defined in the Diagnostic and Statistical Manual of Mental Disorders, fourth edition (DSM-IV) as conduct disorder (CD), oppositional defiant disorder (ODD), and DBD-not otherwise specified (DBD-NOS)—are among the most frequently diagnosed mental disorders in children and adolescents (American Psychiatric Association 1994). CD is typified by a variety of persistent antisocial behaviors, including severe destructiveness and violence, whereas ODD is characterized by a pattern of argumentative, hostile, and defiant behaviors (American Psychiatric Association 1994). In a

1Johnson \& Johnson Pharmaceutical Research and Development, Titusville, New Jersey.

2University Centre of Child and Adolescent Psychiatry, University of Antwerp, Antwerp, Belgium.

3Johnson \& Johnson Research and Development LLC, Beerse, Belgium. 
general pediatric population sample, 3-month prevalence of any DBD is $7.3 \%$, with CD occurring in $5.4 \%$ of the sample and ODD in $1.8 \%$ (Angold et al. 2002). Prevalence of DBD increases in children of subaverage intelligence, reaching $25 \%$ in mentally retarded children (Dosen 1993; Gillberg et al. 1986; Emerson 2003). In addition to disruptive aggression and agitation, children with DBDs have increased risk for substance abuse, risk behaviors, criminality, and poor adult health (Satterfield and Schell 1997; Bardone et al. 1998; Moss and Lynch 2001; Shrier et al. 2003). Compelling evidence suggests that untreated cases are consistently associated with these poor long-term outcomes and high social burden. Adequate treatment of pediatric DBDs is, therefore, essential to minimize both short-term care issues and long-term social and developmental risks.

Strategies for the management of DBDs in children include the combination of behavioral (e.g., contingency management programs, problem solving, and anger management) and medication therapies (Pappadopulos et al. 2003). DBD treatment is complicated by comorbidity with attentiondeficit/hyperactivity disorder (ADHD) in the majority of DBD patients (Kutcher et al. 2004). Combined behavioral modification and medication therapy has also been shown to effectively reduce behavioral disturbances in children with combined ADHD and DBD (Kolko et al. 1999).

Atypical antipsychotics are recommended in patients when DBDs are not controlled through psychosocial interventions and primary psychiatric disease management. Recently, a multinational panel recommended risperidone for $\mathrm{CD}$ because of proven efficacy and tolerability (Kutcher et al. 2004). Risperidone, which can be safely coadministered with methylphenidate, was also recommended in children with ADHD and comorbid CD. A recent post hoc analysis on children treated with risperidone showed that both the efficacy and safety of risperidone were unaffected by the presence or absence of concomitant psychostimulant medication (Aman et al. 2004).

Efficacy of risperidone in reducing disruptive behaviors in children and adolescents with DBDs has been demonstrated in several short-term, double-blind, placebo-controlled, clinical trials (Findling et al. 2000; Buitelaar et al. 2001; van Bellinghen and de Troch 2001; Aman et al. 2002; Snyder et al. 2002). Benefits have consistently been demonstrated within the first few weeks of therapy initiation. Common adverse events (AEs) have typically included mild and transient somnolence and weight gain. Extrapyramidal symptoms (EPSs) with risperidone in these short-term trials have been similar to those seen with placebo. Two 48-week extension studies, treating DBDs in children with subaverage intelligence, with risperidone (mean dosage $=1.5$ $\mathrm{mg}$ /day) showed maintenance of efficacy benefits and good tolerability (Turgay et al. 2002 [ $n=77$ ]; Findling et al. 2004 [ $n=107])$. In both studies, AEs were generally mild to moderate in severity, with discontinuation because of AEs in only $3 \%$ in one study (Turgay et al. 2002) and $10 \%$ in the other (Findling et al. 2004).

Long-term efficacy and tolerability was additionally evaluated in a larger-scale, 1-year, international, open-label study (Croonenberghs et al. 2005). Children and adolescents 5-14 years of age with severe DBDs $(\geq 24$ on the conduct subscale of the Nisonger Child Behavior Rating Form [N-CBRF]) and subaverage intelligence (IQ 35-84) were treated with risperidone (mean modal dosage $=1.7 \pm 0.81$ $\mathrm{mg} /$ day) for 1 year $(n=504: 481$ newly recruited subjects; 23 from a previous doubleblind study). Behavior rating scores improved significantly within 1 week of treatment initiation, with benefits maintained during the 1 year of treatment. The mean N-CBRF conduct problem subscale score decreased from 32.9 to 17.0 (48\%). In addition, cognition scores improved significantly on both continuous performance and verbal testing. Of the 504 patients, $43(8.5 \%)$ discontinued treatment because of AEs. EPSs were infrequent, required anti-EPS medications in only 5 patients, and led to treatment discontinuation in only 6 patients. Two patients developed dyskinesia, which resolved a few weeks after the study medication was discontinued. Prolactin levels increased transiently after 4 weeks of treatment, and, in total, for 56 patients (11\%), the investigator reported hyperprolactinemia. Po- 
tentially prolactin-related AEs included: Gynecomastia $(n=25$, resolving in 8 while continuing risperidone), menstrual disturbance $(n=$ $6)$, and galactorrhea $(n=1)$. Based upon Tanner staging, there were no signs of delayed sexual maturation. These findings are consistent with previous studies, where elevated levels of prolactin were observed upon treatment with risperidone, but no effect on sexual maturation was observed (Findling et al. 2003; Dunbar et al. 2004). Although there were several potentially prolactin-related AEs, it should be noted that some of these, such as gynecomastia in boys over the age of 10 years, often also present as a normal part of puberty (Findling et al. 2003).

Treatment of DBDs often requires long-term pharmacotherapy, with the goal of maintaining behavioral control without development of significant AEs. This study, therefore, was designed to continue long-term follow-up of children who had successfully participated in an initial year of risperidone therapy in the open-label study outlined above (Croonenberghs et al. 2005). All of the patients included in this long-term, 1-year extension study (referred to as Year 2) were enrolled within 7 days after taking the final medication in the initial 1-year open-label study (referred to as Year 1).

Both efficacy and safety variables were measured. Specific safety concerns associated with some atypical antipsychotics, which are important factors in selecting long-term therapy in pediatric patients, include potential prolactin-related AEs, glucose intolerance, EPS, and weight gain (Stigler et al. 2001). These were followed over the 2-year period. In addition, the effect on cognition was assessed, as this was an important consideration for this population.

\section{METHODS}

The protocol and written, informed consent were approved by local independent ethics committees. This study was conducted in accordance with good clinical practice and the Declaration of Helsinki. All patients gave informed consent prior to study enrollment. Eligible children and adolescents (6-15 years of age) were required to have a DSM-IV diagnosis of CD, ODD, or DBD-NOS, plus borderline intellectual functioning or mild-to-moderate mental retardation (IQ 35-84). The DSM-IV diagnosis was made by the investigator, upon enrollment to the original Year 1 study, at which time patients were also required to have a total rating of $\geq 24$ in the conduct problem subscale of the N-CBRF. Patients with a diagnosis of pervasive developmental disorder (PDD), schizophrenia, or other psychotic disorders were excluded from the study. The intelligence of each child was assessed using the Stanford-Binet Intelligence Scale (Thorndike et al. 1986) or the Wechsler Intelligence Scale for Children, third edition (Weschler 1974). In addition, patients were only eligible if they had completed the Year 1 open-label risperidone treatment within 7 days of enrolling in the extension study and were expected to benefit from continued risperidone treatment.

Patients enrolled in this study were treated with risperidone oral solution $(1 \mathrm{mg} / \mathrm{mL})$ administered once- or twice-daily in water, orange juice, milk, or black coffee. Dosage was determined for each patient individually by the investigator, based on treatment efficacy and tolerability. The maximum permitted daily risperidone dose change was 0.02 $\mathrm{mg} / \mathrm{kg} /$ day. The maximum total daily dosage allowed was $4 \mathrm{mg}$. Use of concomitant medications was permitted, with all medications being recorded. Use of psychostimulants as concomitant medication was permitted if the medication had been stabilized for at least 30 days prior to entry into the initial trial, and the dose was to be kept constant throughout the trial.

The start of the initial Year 1 trial was set as baseline 1; baseline 2 was the enrollment in the Year 2 extension study (month 12 of risperidone treatment). Treatment efficacy was determined with caregiver- and physician-rated symptom severity measures. The N-CBRF and Aberrant Behavior Checklist (ABC) were both obtained at baseline 2, every 6 months (treatment months 18 and 24), and at endpoint. The 66-item N-CBRF allows caregivers to rate the severity of a variety of behaviors, with separate scores identified for 10 subscales grouped into two broad categories: Positive social be- 
havior and problem behavior, the latter of which includes the conduct problem subscale (Aman et al. 1996). The ABC is a 58-item caregiver-scored test, producing a total score and five subscale scores (irritability/agitation, lethargy/social withdrawal, stereotypic behavior, hyperactivity/noncompliance, and inappropriate speech; Aman et al. 1985). Investigator-rated Clinical Global Impression of Severity (CGI-S) scores were obtained at baseline 2 and at 3-month intervals during the study (treatment months 13,15, 18, 21, and 24 or endpoint). The CGI-S of symptoms is scored on a scale from 1 (absent) to 7 (extremely severe) (Guy 1976).

Change in the conduct problem subscale of the N-CBRF at endpoint was the primary efficacy measure. A mixed-model statistical approach with repeated measures was used to illustrate changes over the 2-year period. Significant differences were identified, using a paired $t$ test, with significance set at $<0.05$ versus baseline 1 . Changes from the baselines in other N-CBRF subscales, ABC total and subscale scores, and CGI-S were secondary efficacy measures. Secondary efficacy measures were evaluated using descriptive analyses.

Safety and tolerability were assessed by recording weight, height, and any spontaneous reports of AEs at baseline 2 (month 12) and risperidone treatment months $13,15,18,21$, and 24 or endpoint. To give a better assessment of weight change, mean weight and body mass index (BMI) Z-scores were plotted over time. At each time point, weight and BMI were transformed to a Z-score, given the subject's age in months and gender. The Z-score describes how far a child's weight is from the average for children of the same height. Zscores were derived using a SAS program available at the U.S. Centers for Disease Control (CDC) website; www.cdc.gov/nccdphp/ dnpa/growthcharts/sas.htm. Based on the May 30, 2000 CDC growth charts, parameters were estimated for transforming a weight or BMI value to a Z-score as a function of age (in 0.5 -month increments) and gender for children 2-20 years of age. Vital signs, electrocardiograms (ECGs), Extrapyramidal Symptoms Rating Scale (ESRS; Chouinard et al. 1980), cognitive testing, and laboratory tests were performed at enrollment, every 6 months, and endpoint. Cognitive testing included a computerized Continuous Performance Task (CPT) and a modified California Verbal Learning Test-Children's Version. The CPT consisted of both an easy and hard test (described in Croonenberghs et al. 2005). For the verbal learning test, 10 words were presented orally or pictorially. Tests included five trials recording the number of words recalled after a short delay (score range $=0-50$ correctly recalled words), one trial recording the number of words recalled after a long delay (range $=0-10$ correctly recalled words), and recognition of the original 10 words in a list of 20 words (range $=0-20$ correct identifications). Laboratory tests included blood sampling for hematology, blood chemistry, prolactin, and insulin-like growth factor I, and a urinalysis for protein, glucose, and occult blood. A physical examination, including Tanner staging, was performed at enrollment and endpoint. Safety and tolerability analyses were performed on all patients treated with at least a single risperidone dose. Separate analyses were performed for children (defined in this paper as $<12$ years old) and adolescents ( $\geq 12$ years old). Prolactin levels were separately assessed for boys and girls. Safety and tolerability parameters were evaluated for change from baselines using mean scores.

\section{RESULTS}

\section{Patients}

Five hundred four patients participated in the original Year 1 open-label study (Croonenberghs et al. 2005), 23 of whom had already participated in a previous double-blind study (Snyder et al. 2002). Of the 481 newly enrolled patients, only a subset was eligible for the Year 2 extension study: 48 patients enrolled. The reason for this low enrollment rate was the late approval of the protocol for this extension trial; therefore, only 48 patients were able to meet the criteria of entering the extension trial no later than 7 days after taking the last dose of medication in the initial trial. Patient characteristics of the extension study were similar 
to those of the entire original patient pool (Table 1). Patients included 25 children (52\%) and 23 adolescents (48\%), with a mean age at the time of enrollment in the extension study of $11.0 \pm 2.35$ years. Mean weight and BMI, respectively, were $45.3 \pm 16.54 \mathrm{~kg}$ and $20.7 \pm 4.79$ $\mathrm{kg} / \mathrm{m}^{2}$. All 48 patients were included in the safety analysis, with 46 completing at least one efficacy assessment. This study was completed by 33 patients $(69 \%)$. Reasons for study discontinuations were: $\operatorname{AE~}(n=6 ; 13 \%)$; insufficient response $(n=2 ; 4 \%)$; patient ineligible to continue study $(n=2 ; 4 \%)$; patient withdrew consent $(n=2 ; 4 \%)$; patient noncompliant $(n=$ $1 ; 2 \%)$; other $(n=2 ; 4 \%)$. Concomitant medication(s) were used by 27 patients (56\%) at some time during the study. The most frequently administered medications were: Methylphenidate hydrochloride $(n=7 ; 15 \%)$, followed by the analgesic, paracetamol (acetaminophen, $n$ $=5 ; 10 \%)$. The effect of concomitant medication on outcome was not investigated.

The mean duration of therapy in the Year 2 extension trial was 330.5 days (range $=47-457$ days). The risperidone mean daily dosage was $0.041 \mathrm{mg} / \mathrm{kg} /$ day (range $=0.01-0.09$ $\mathrm{mg} / \mathrm{kg} /$ day) or $1.83 \mathrm{mg} /$ day (range = $0.44-3.89 \mathrm{mg} /$ day). The majority of patients received a mean dosage of $<3 \mathrm{mg} /$ day $(n=44)$.

\section{Efficacy assessment}

Efficacy assessments at baselines 1 and 2 were available for all 48 patients, with endpoint data available for 46 patients. The NCBRF conduct problem subscale, which decreased during the first weeks of risperidone therapy, and continued to show an improvement (decrease) over time in the preceding Year 1 study, maintained its efficacy during this Year 2 extension (mean score at baseline $1=32.3 \pm 7.1$; mean at baseline $2=$ $15.2 \pm 10.0$; mean at extension study endpoint $=16.5 \pm 11.6 ; p<0.001)$. Patients treated during the Year 1 study only and those who continued to take risperidone during the Year 2 extension showed similar responses, indicating that these populations were not different from each

Table 1. Pretreatment (Baseline 1) Demographics for Patients Entering the Initial Year 1 Open-Label Risperidone Treatment Study and Those Continuing With THE YEAR 2 EXTENSION

\begin{tabular}{lcc}
\hline & $\begin{array}{c}\text { Original Year } 1 \text { study } \\
(n=481)\end{array}$ & $\begin{array}{c}\text { Year } 2 \text { extension } \\
(n=48)\end{array}$ \\
\hline Mean age, years \pm SD & $9.7 \pm 2.4$ & $9.9 \pm 2.3$ \\
Gender $n(\%)$ & $400(83)$ & $42(88)$ \\
Boys & $81(17)$ & $6(13)$ \\
Girls & & \\
DSM-IV Axis I diagnoses $n(\%)$ & $10(2)$ & $1(2)$ \\
ADHD & $49(10)$ & $12(25)$ \\
ADHD + DBD-NOS & $96(20)$ & $10(21)$ \\
ADHD + CD & $90(19)$ & $6(13)$ \\
ADHD + ODD & $32(7)$ & $14(29)$ \\
DBD-NOS & $118(25)$ & $2(4)$ \\
CD & $86(18)$ & $20(42)$ \\
ODD & & $18(38)$ \\
DSM-IV Axis II diagnoses $n$ (\%) & $178(37)$ & $10(21)$ \\
Borderline intellectual functioning & $206(43)$ & $64.2 \pm 14.1$ \\
Mild mental retardation & $96(20)$ & $36.9 \pm 14.4$ \\
Moderate mental retardation & $64.0 \pm 13.7$ & $36.5 \pm 13.7$ \\
Mean IQ \pm SD & &
\end{tabular}

$\mathrm{ADHD}=$ attention-deficit/hyperactivity disorder; $\mathrm{CD}=$ conduct disorder; DBD-NOS = disruptive behavior disorder-not otherwise specified; DSM-IV = Diagnostic and Statistical Manual of Mental Disorders, fourth edition; IQ = intelligence quotient; ODD = oppositional defiant disorder; $\mathrm{SD}=$ standard deviation. 
other (Fig. 1). The other problem behavior NCBRF subscales similarly decreased during the initial year of treatment with risperidone, whereas the scores on the positive social behavior subscales increased. These effects were also maintained over the long term (Fig. 2).

$A B C$ subscale scores showed a similar pattern to that seen for the N-CBRF. Mean ABC scores decreased during the first year of risperidone therapy, with benefits maintained during the Year 2 extension (Table 2).

CGI benefits were also maintained over the long term (Fig. 3). At baseline 1, 45 patients had moderate to extremely severe symptoms, whereas 1 patient had mild symptoms. After

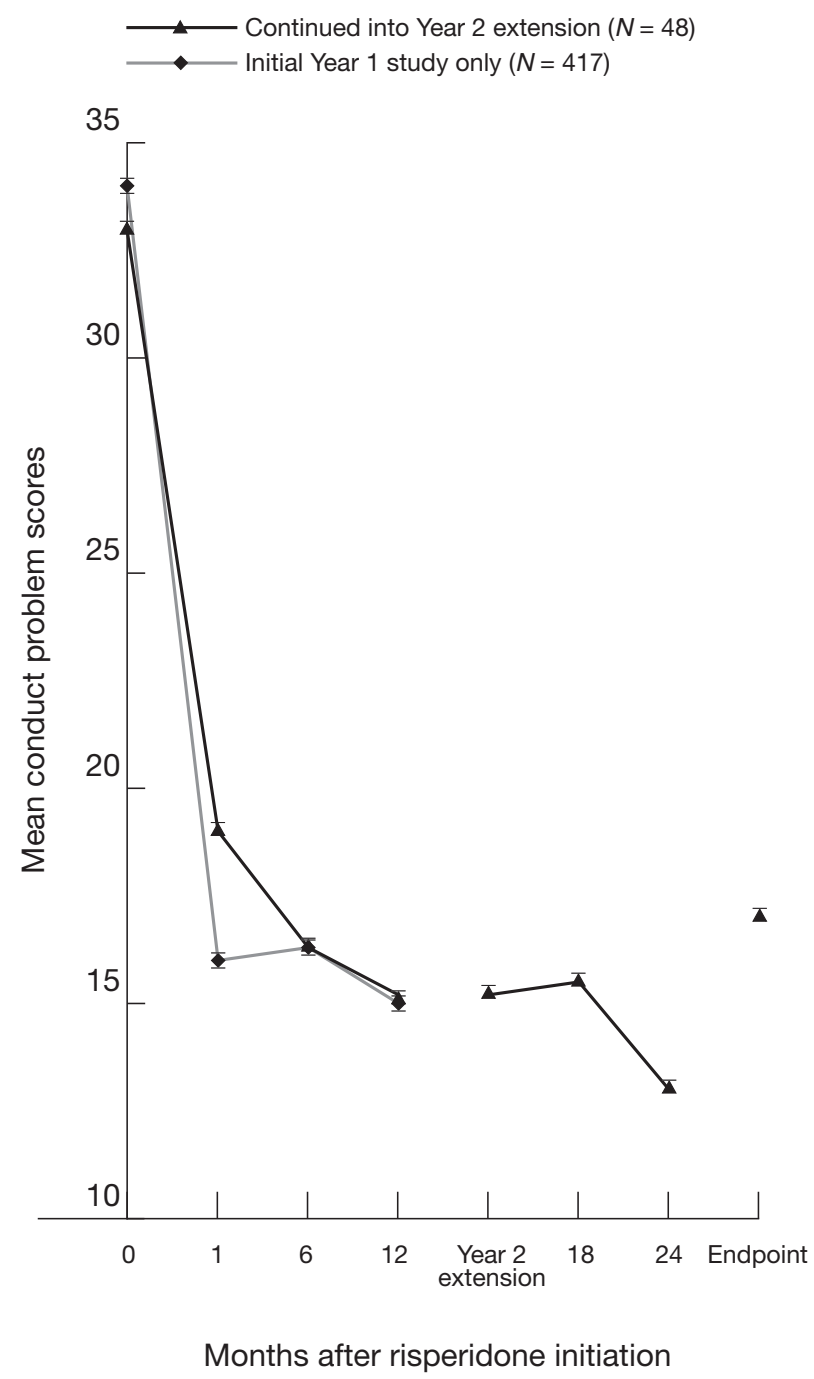

FIG. 1. Mean scores ( \pm standard error) on Nisonger Child Behavior Rating Form (N-CBRF) conduct problem subscale during Year 1 and Year 2 of risperidone treatment. the 1st year of risperidone therapy, 38 of those 46 patients had no symptoms to mild symptoms. These benefits were generally maintained during this Year 2 extension, with 33 patients having no symptoms to mild symptoms at study endpoint.

\section{Safety assessment}

Safety data were available for all 48 patients. Treatment-emergent AEs occurred in $64 \%$ of children and $78 \%$ of adolescents and were generally mild to moderate in severity. Frequency of individual AEs was similar between children and adolescents. AEs that resulted in discontinuation of treatment for 6 patients (13\%) included worsening CD, hyperkinesia, gynecomastia, pain, and depression.

The incidence of treatment-emergent AEs that occurred in $>5 \%$ of patients (AEs that are either new in onset or aggravated in severity during the extension study) are summarized in Table 3. There was a numerical reduction in the percentage of patients reporting AEs during the second year of treatment. Several AEs that had been reported in $>10 \%$ of patients during the initial year of treatment were reported infrequently $(<10 \%)$ during the Year 2 extension: Somnolence $(31.3 \%$ incidence in Year 1 vs. $8.3 \%$ in Year 2), rhinitis (20.8\% vs. $8.3 \%)$, fatigue $(16.7 \%$ vs. $2.1 \%)$, coughing $(10.4 \%$ vs. $4.2 \%)$, and headache $(16.7 \%$ vs. $4.2 \%)$.

EPS-related AEs were reported in 2 children and 3 adolescents. One of these patients was treated with a risperidone dosage (4.3 $\mathrm{mg}$ /day) in excess of the maximum allowed dosage in this trial. There were no cases of tardive dyskinesia. All EPS-related AEs were mild to moderate, with treatment discontinued in only 1 patient with hyperkinesia. Mean investigator-rated ESRS scores were low and decreased slightly during the second year of risperidone treatment. Mean ESRS at baseline 2 was $1.0 \pm 2.1$ versus $0.8 \pm 2.3$ at endpoint.

There were no clinically relevant changes in blood hematology, chemistry, or urinalysis testing. No glucose-related AEs were reported. The mean prolactin level in girls $(n=5)$ was $10.1 \pm 5.0 \mathrm{ng} / \mathrm{mL}$ at baseline 1 and $34.0 \pm 14.0$ $\mathrm{ng} / \mathrm{mL}$ at endpoint of this Year 2 extension 
FIG. 2. Mean ( \pm standard error) Nisonger Child Behavior Rating Form (N-CBRF) subscale scores.

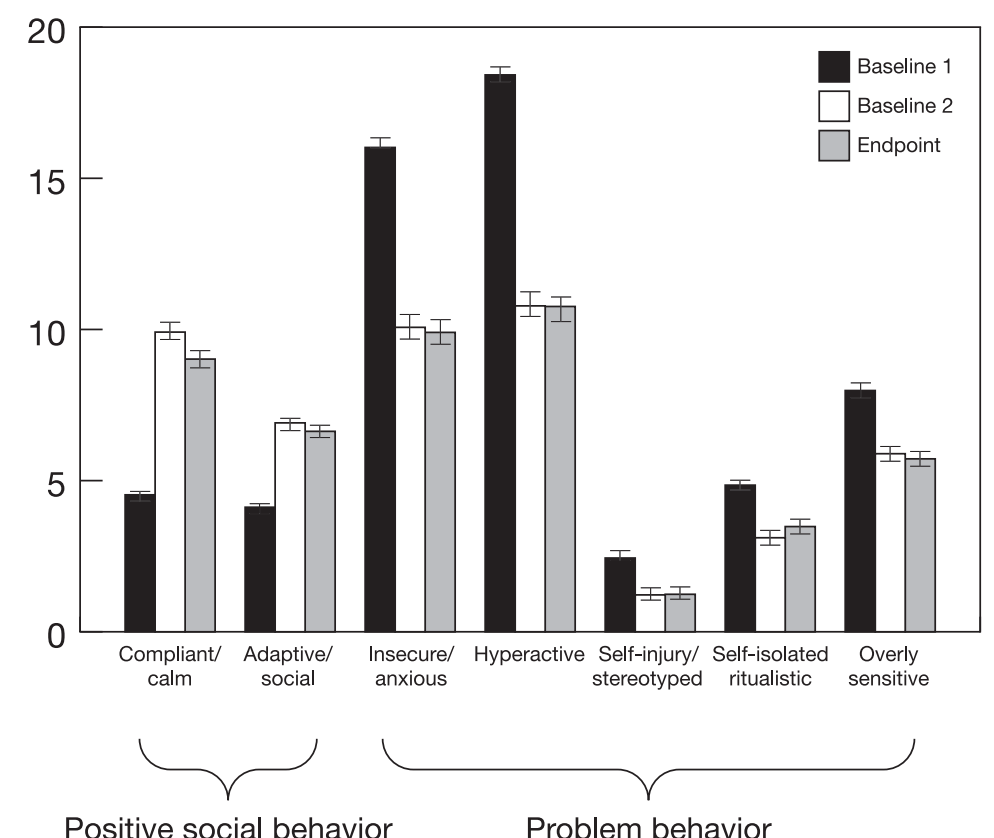

Positive social behavior
Problem behavior study. Mean prolactin in boys $(n=33)$ at baseline 1 was $7.7 \pm 8.3 \mathrm{ng} / \mathrm{mL}$ and $25.5 \pm 55.1$ $\mathrm{ng} / \mathrm{mL}$ at endpoint. Increase in mean prolactin in boys was highly influenced by 1 patient. The median prolactin level in boys was $4.60 \mathrm{ng} / \mathrm{mL}$ at baseline 1 and $15.0 \mathrm{ng} / \mathrm{mL}$ at endpoint. During the extension trial new cases of potentially prolactin-related AEs occurred infrequently: Gynecomastia in 3 boys and amenorrhea in 1 girl. Two cases of gynecomastia were rated as severe and led to treatment discontinuation. Importantly, as has been previously observed (Findling et al. 2003), occurrence of gynecomastia was not related to increases in serum prolactin levels. In every case, normal prolactin levels were obtained in patients with gynecomastia, with highest levels not occurring at the time of clinical gynecomastia.
Analysis of Tanner staging demonstrated no effect of risperidone treatment on sexual maturation.

There were no clinically significant findings on vital signs or ECG measurements. Weight increase was reported for 3 patients (6.3\%). Mean increases in weight and BMI were greatest during the first year of risperidone treatment, with measures stable during the Year 2 extension. Changes in weight and BMI Zscores over the 2 years are shown in Figures 4 and 5, respectively. Based upon Z-scores over time, long-term weight changes stabilized after the first 3-6 months of therapy and did not increase beyond normal growth thereafter.

Cognitive testing showed small improvements during the Year 2 extension. CPT and modified verbal testing showed small but clin-

Table 2. Aberrant Behavior Checklist (ABC) Subscale Scores

\begin{tabular}{lrrr}
\hline \multicolumn{1}{c}{ ABC subscale score } & Baseline 1 & Baseline 2 & Endpoint \\
\hline Irritability/agitation & $16.8 \pm 7.0$ & $9.8 \pm 7.8$ & $10.9 \pm 9.0$ \\
Lethargy/social withdrawal & $6.2 \pm 5.7$ & $4.0 \pm 5.9$ & $4.0 \pm 6.2$ \\
Stereotypic behavior & $2.6 \pm 4.4$ & $1.2 \pm 2.6$ & $1.5 \pm 2.7$ \\
Hyperactivity/noncompliance & $29.8 \pm 9.7$ & $15.0 \pm 9.6$ & $16.0 \pm 10.5$ \\
Inappropriate speech & $3.6 \pm 3.2$ & $2.2 \pm 3.3$ & $2.4 \pm 2.7$ \\
\hline
\end{tabular}

Baseline 1 = values prior to treatment in the original Year 1 study (Croonenberghs et al. 2005); Baseline 2 = values at start of Year 2 extension. 

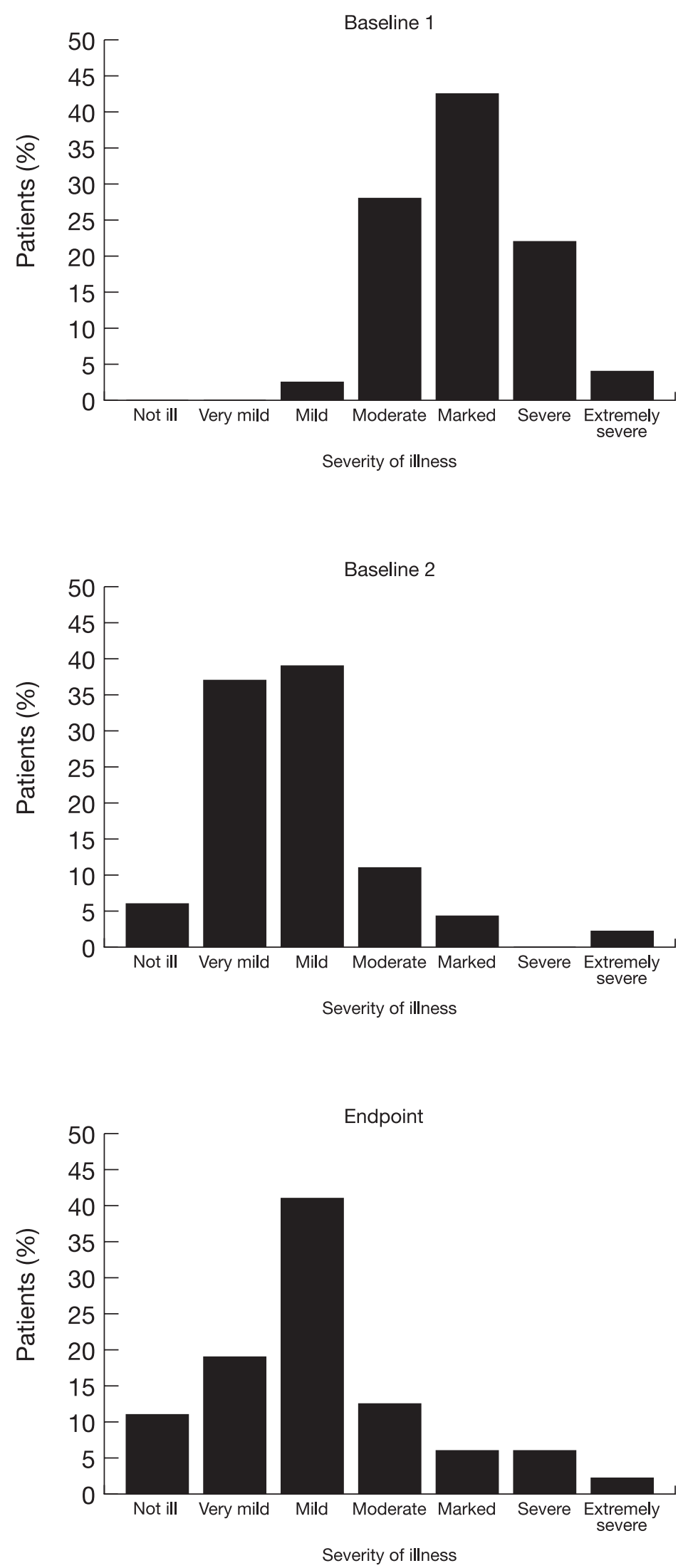

FIG. 3. Frequency distribution of Clinical Global Impression of Severity (CGI-S) ratings: percentage of patients in each severity category. 


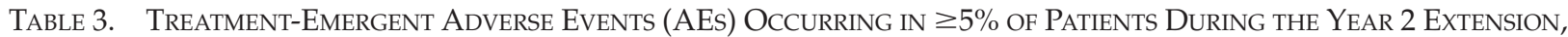
Compared With Prevalence of the SAme AEs During the First Treatment Year

\begin{tabular}{|c|c|c|c|c|c|}
\hline \multirow[b]{3}{*}{$\begin{array}{l}\text { Number } \\
\text { of patients } \\
\text { with AE (\%) }\end{array}$} & \multicolumn{2}{|c|}{ Original Year 1 study } & & & \\
\hline & \multirow{2}{*}{$\begin{array}{l}\text { Patients } \\
\text { continuing } \\
\text { into Year } 2 \\
\text { extension } \\
(N=48)\end{array}$} & \multirow{2}{*}{$\begin{array}{l}\text { Patients not } \\
\text { continuing } \\
\text { into Year } 2 \\
\text { extension } \\
(N=433)\end{array}$} & \multicolumn{3}{|c|}{ Year 2 extension } \\
\hline & & & $\begin{array}{c}\text { All } \\
\text { patients } \\
(N=48)\end{array}$ & $\begin{array}{l}\text { Children } \\
(n=25)\end{array}$ & $\begin{array}{c}\text { Adolescents } \\
\quad(n=23)\end{array}$ \\
\hline All AEs & $43(89.6)$ & $396(91.5)$ & $34(70.8)$ & $16(64.0)$ & $18(78.3)$ \\
\hline \multicolumn{6}{|l|}{ Psychiatric symptoms } \\
\hline Aggression & $7(14.6)$ & $23(5.3)$ & $3(6.3)$ & $2(8.0)$ & $1(4.3)$ \\
\hline Agitation & $3(6.3)$ & $20(4.6)$ & $5(10.4)$ & $1(4.0)$ & $4(17.4)$ \\
\hline Somnolence & $15(31.3)$ & $123(28.4)$ & $4(8.3)$ & $1(4.0)$ & $3(13.0)$ \\
\hline Condition aggravated & $2(4.2)$ & $19(4.4)$ & $3(6.3)$ & $1(4.0)$ & $2(8.7)$ \\
\hline Rhinitis & $10(20.8)$ & $118(27.3)$ & $4(8.3)$ & $3(12.0)$ & $1(4.3)$ \\
\hline Abdominal pain & $2(4.2)$ & $33(7.6)$ & $3(6.3)$ & $1(4.0)$ & $2(8.7)$ \\
\hline Increased saliva & $4(8.3)$ & $31(7.2)$ & $4(8.3)$ & $1(4.0)$ & $3(13.0)$ \\
\hline Body pain & $2(4.2)$ & $6(1.4)$ & $2(4.2)$ & 0 & $2(8.7)$ \\
\hline Gynecomastia & $4(8.3)$ & $18(4.2)$ & $3(6.3)$ & $1(4.0)$ & $2(8.7)$ \\
\hline Weight increase & $11(22.9)$ & $72(16.6)$ & $3(6.3)$ & $2(8.0)$ & $1(4.3)$ \\
\hline
\end{tabular}

ically meaningful improvements in all measures (Table 4). No statistical testing was performed on the cognitive measures.

\section{DISCUSSION}

Risperidone is recommended by international experts for the treatment of DBDs (Kutcher et al. 2004), and this study assessed its long-term effectiveness and safety over a cumulative 2-year period. Children and adolescents (6-15 years of age), with DBD and mild to moderate mental retardation or borderline intellectual functioning, who initially benefited from oral risperidone treatment continued to benefit from low-dose risperidone during long-term treatment for up to 2 years. Efficacy benefits occurring during the initial year of therapy across a broad array of symptoms con-
FIG. 4. Mean change in weight Z-scores ( \pm standard error) during Year 1 and Year 2 of risperidone treatment.

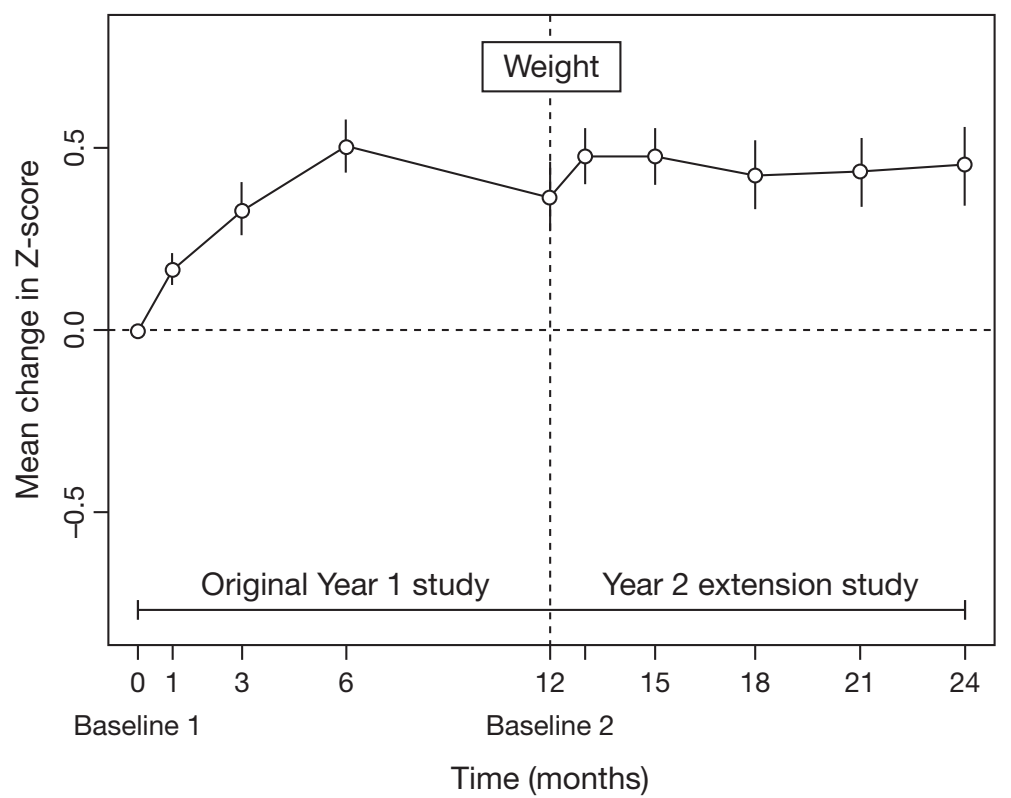




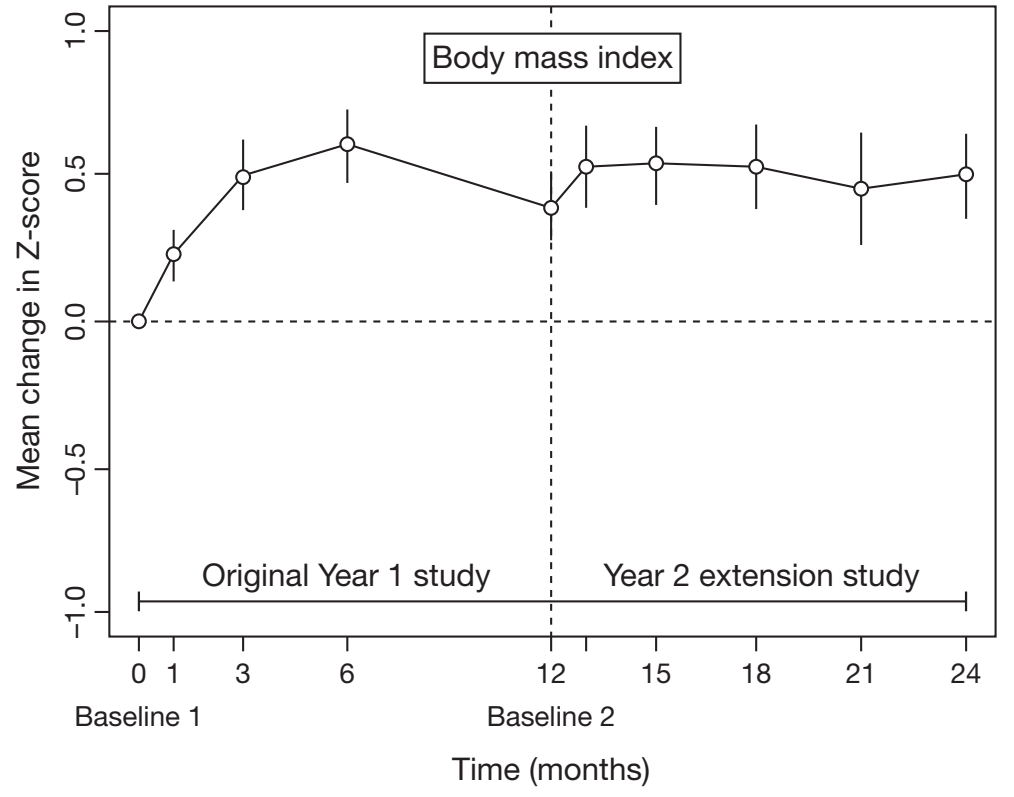

FIG. 5. Mean change in body mass index (BMI) Z-scores ( \pm standard error) during Year 1 and Year 2 of risperidone treatment. tinued to accrue and were maintained during the subsequent year of treatment.

Long-term safety and tolerability was confirmed by review of AEs, laboratory measures, ECGs, physical examinations, and cognitive testing. AEs led to treatment discontinuation for only 6 patients (13\%). The type of AEs experienced during the second year were similar to those reported during the first year of treatment, with no unexpected AEs. In addition, the incidence of several AEs, such as somnolence and rhinitis, decreased in the extension study. Small increases in weight experienced during the initial year of risperidone treatment stabilized during the second year. Increases in prolactin were difficult to interpret, owing to small sample size and marked interpatient variability, and were not correlated to potential prolactin-related AEs. Importantly, elevated prolactin levels were not correlated with the 3 cases of gynecomastia. For the patient with amenorrhea, the prolactin level was increased 1 month after the AE. There were no glucose-related AEs. The tolerability of risperidone treatment is particularly important, as it has recently been shown, in a placebocontrolled trial, that risperidone can prevent relapse of DBD symptoms in children, indicating that long-term treatment may be beneficial (Reyes et al. 2006).

Table 4. Mean Cognitive Testing Scores

\begin{tabular}{lccc}
\hline & $\begin{array}{c}\text { Baseline } 1 \\
\text { score } \pm S D\end{array}$ & $\begin{array}{c}\text { Baseline } 2 \\
\text { score } \pm S D\end{array}$ & $\begin{array}{c}\text { Endpoint } \\
\text { score } \pm \text { SD }\end{array}$ \\
\hline Continuous performance task & & & \\
$\quad$ Easy hits & $32.4 \pm 10.3$ & $33.8 \pm 10.5$ & $34.5 \pm 10.3$ \\
Easy misses & $7.3 \pm 10.1$ & $6.2 \pm 10.5$ & $5.5 \pm 10.3$ \\
Hard hits & $33.8 \pm 6.2$ & $35.3 \pm 8.0$ & $37.9 \pm 4.0$ \\
Hard misses & $6.2 \pm 6.2$ & $4.7 \pm 8.0$ & $2.1 \pm 4.0$ \\
Verbal test & $27.5 \pm 10.4$ & $31.8 \pm 10.7$ & $32.8 \pm 12.2$ \\
Short delay recall & $5.4 \pm 2.8$ & $6.0 \pm 3.3$ & $6.7 \pm 2.8$ \\
Long delay recall & $15.8 \pm 5.0$ & $16.9 \pm 4.5$ & $17.0 \pm 5.5$ \\
$\quad$ Recognition total correct & & & \\
\hline
\end{tabular}

Baseline 1 = values prior to treatment in the original Year 1 study (Croonenberghs et al. 2005); Baseline 2 = values at start of Year 2 extension; SD = standard deviation. 
Other medications used in the treatment of DBD include typical neuroleptics and anticonvulsive medications, which can interfere with cognition owing to the side effects of sedation and somnolence (Aman and Singh 1988; Kaplan et al. 1994). Interestingly, in this study, cognitive testing demonstrated small but meaningful improvements in both CPT and verbal testing. Because of its open-label nature, this study could not distinguish between improvements related directly to risperidone therapy or other factors, such as environment, better behavioral control, or simply normal development over the course of the study. However, irrespective of the underlying reason, the preservation of cognitive abilities is especially important in this population of children and adolescents, where intellectual functioning is already impaired.

A small proportion of patients $(n=9 ; 19 \%)$ were treated with concomitant psychostimulant therapy. This treatment was to be stabilized prior to enrollment and kept stable during the study with risperidone. Although, in this study, the influence of the use of this medication on treatment outcome was not assessed owing to the small patient number, a previous study has shown that concomitant psychostimulant medication does not have an effect on either the efficacy or the tolerability of risperidone in the treatment of DBD (Aman et al. 2004). Furthermore, international consensus guidelines have recommended combinatorial treatment with risperidone and psychostimulants in patients with ADHD and comorbid CD where psychostimulant treatment alone is insufficient to control disruptive behavioral symptoms (Kutcher et al., 2004).

\section{Limitations}

Study limitations included the lack of a control group, small sample size, and selection of patients who previously demonstrated benefit from risperidone. Delay in study initiation limited the number of eligible patients, and less than $10 \%$ of those enrolled in the initial open-label risperidone treatment study continued into the extension study. Although this represented a minority of the original study population, patient demographics and diag- noses were similar between the original and extension treatment populations. Given the open-label nature of the study, no firm conclusions about the efficacy of risperidone can be drawn, as any effect cannot be attributed to risperidone alone. Other factors, such as concomitant medication, changes in environment, and developmental changes, could also have influenced the findings of this study.

\section{Clinical implications}

This extension study demonstrated that the benefits achieved in reducing the symptoms of DBDs could be maintained for up to 2 years. Importantly, these benefits were achieved without negative cognitive or developmental AEs.

\section{CONCLUSIONS}

In summary, low-dosage oral risperidone provides good long-term treatment efficacy, safety, and tolerability in children and adolescents with DBDs and subaverage intelligence.

\section{ACKNOWLEDGMENTS}

This study was supported by Johnson \& Johnson Pharmaceutical Research and Development. The authors would like to thank all the investigators who were involved in the trial.

\section{REFERENCES}

Aman MG, Binder C, Turgay A: Risperidone effects in the presence/absence of psychostimulant medicine in children with ADHD, other disruptive behavior disorders, and subaverage IQ. J Child Adolesc Psychopharmacol 14:243-254, 2004.

Aman MG, De Smedt G, Derivan A, Lyons B, Findling RL: Double-blind, placebo-controlled study of risperidone for the treatment of disruptive behaviors in children with subaverage intelligence. Am J Psychiatry 159:1337-1346, 2002.

Aman MG, Singh NN: Patterns of drug use, methodological considerations, measurements techniques, and future trends. In: Psychopharmacology of the Developmental Disabilities. Edited 
by Aman MG, Singh NN. New York, SpringerVerlag, 1988, pp 1-28.

Aman MG, Singh NN, Stewart AW, Field CJ: The Aberrant Behavior Checklist: A behavior rating scale for the assessment of treatment effects. Am J Ment Defic 89:485-491, 1985.

Aman MG, Tasse MJ, Rojahn J, Hammer D: The Nisonger CBRF: A child behavior rating form for children with developmental abnormalities. Res Dev Disabl 17:41-57, 1996.

American Psychiatric Association: Diagnostic and Statistical Manual of Mental Disorders, 4th ed. (DSM-IV), Washington (DC), American Psychiatric Association, 1994.

Angold A, Erkanli A, Farmer EM, Fairbank JA, Burns BJ, Keeler G, Costello EJ: Psychiatric disorder, impairment, and service use in rural AfricanAmerican and white youth. Arch Gen Psychiatry 59:893-901, 2002.

Bardone AM, Moffitt TE, Caspi A, Dickson N, Stanton WR, Silva PA: Adult physical health outcomes of adolescent girls with conduct disorder, depression, and anxiety. J Am Acad Child Adolesc Psychiatry 37:594-601, 1998.

Buitelaar JK, van der Gaag RJ, Cohen-Kettenis P, Melman CT: A randomized, controlled trial of risperidone in the treatment of aggression in hospitalized adolescents with subaverage cognitive abilities. J Clin Psychiatry 62:239-248, 2001.

Chouinard G, Ross-Canard A, Annable L, Jones BD: The Extrapyramidal Symptoms Rating Scale. Can J Neurol Sci 8:233, 1980.

Croonenberghs J, Fegert JM, Findling RL, De Smedt G, Van Dongen S, and the Risperidone Disruptive Behavior Study Group: Risperidone in children with disruptive behavior disorders: A 1-year, open-label study of 504 patients. J Am Acad Child Adolesc Psychiatry 44:64-72, 2005.

Dosen A: Diagnosis and treatment of behavioral disorders in mentally retarded individuals: The state of the art. J Intellect Disabil Res 37(Suppl 1):1-7, 1993.

Dunbar F, Kusumakar V, Daneman D, Schulz M: Growth and sexual maturation during long-term treatment with risperidone. Am J Psychiatry 161:918-920, 2004.

Emerson E: Prevalence of psychiatric disorders in children and adolescents with and without intellectual disability. J Intellect Disabil Res 47:51-58, 2003.

Findling RL, McNamara NK, Branicky LA, Schluchter MD, Lemon E, Blumer JL: A doubleblind pilot study of risperidone in the treatment of conduct disorder. J Am Acad Child Adolesc Psychiatry 39:509-516, 2000.

Findling RL, Kusumakar V, Daneman D, Moshang T, De Smedt G, Binder C: Prolactin levels during long-term risperidone treatment in children and adolescents. J Clin Psychiatry 64:1362-1369, 2003.
Findling RL, Aman MG, Eerdekens M, Derivan A, Lyons B: Long-term, open-label study of risperidone in children with severe disruptive behaviors and below-average IQ. Am J Psychiatry 161:677-684, 2004.

Gillberg C, Persson E, Grufman N, Themner U: Psychiatric disorders in mildly and severely mentally retarded urban children and adolescents: Epidemiological aspects. Br J Psychiatry 149:68-74, 1986.

Guy W: Clinical global impressions. In: ECDEU Assessment Manual for Psychopharmacology, Revised. Rockville (Maryland), National Institute of Mental Health, 1976, pp 217-222.

Kaplan SL, Simms RM, Busner J: Prescribing practices of outpatient child psychiatrists. J Am Acad Child Adolesc Psychiatry 33:35-44, 1994.

Kolko DJ, Bukstein OG, Barron J: Methylphenidate and behavior modification in children with ADHD and comorbid ODD or CD: Main and incremental effects across settings. J Am Acad Child Adolesc Psychiatry 38:578-586, 1999.

Kutcher S, Aman M, Brooks SJ, Buitelaar J, van Daalen E, Fegert J, Findling RL, Fisman S, Greenhill LL, Huss M, Kusumakar V, Pine D, Taylor E, Tyano S: International consensus statement on attention-deficit/hyperactivity disorder (ADHD) and disruptive behavior disorders (DBDs): Clinical implications and treatment practice suggestions. Eur Neuropsychopharmacol 14:11-28, 2004. Moss HB, Lynch KG: Comorbid disruptive behavior disorder symptoms and their relationship to adolescent alcohol use disorders. Drug Alcohol Depend 64:75-83, 2001.

Pappadopulos E, MacIntyre II JC, Crimson ML, Findling RL, Malone RP, Derivan A, Schooler N, Sikich L, Greenhill L, Schur SB, Felton CJ, Kranzler H, Rube DM, Sverd J, Finnerty M, Ketner S, Siennick SE, Jensen PS: Treatment recommendations for the use of antipsychotics for aggressive youth (TRAAY). Part II. J Am Acad Child Adolesc Psychiatry 42:145-161, 2003.

Reyes M, Buitelaar J, Toren P, Augustyns I, Eerdekers M: A Randomized, Double-Blind, Placebo-Controlled Study of Risperidone Maintenance Treatment in Children and Adolescents with Disruptive Behavior Disorders. Am J Psych 163:402-410, 2006.

Satterfield JH, Schell A: A prospective study of hyperactive boys with conduct problems and normal boys: Adolescent and adult criminality. J Am Acad Child Adolesc Psychiatry 36:1726-1735, 1997.

Shrier LA, Harris SK, Kurland M, Knight JR: Substance use problems and associated psychiatric symptoms among adolescents in primary care. Pediatrics 111(6 Pt 1):e669-705, 2003.

Snyder R, Turgay A, Aman M, Binder C, Fisman S, Caroll A; Risperidone Study Group: Effects of risperidone on conduct and disruptive behavior 
disorders in children with subaverage IQs. J Am Acad Child Adolesc Psychiatry 41:1026-1036, 2002.

Stigler KA, Potenza MN, McDougle CJ: Tolerability profile of atypical antipsychotics in children and adolescents. Paediatr Drugs 3:927-942, 2001.

Thorndike RL, Hagen EP, Sattler JM: Stanford-Binet Intelligence Scales, 4th ed. Chicago (Illinois), Riverside Publishing, 1986.

Turgay A, Binder C, Snyder R, Fisman S: Long-term safety and efficacy of risperidone for the treatment of disruptive behavior disorders in children with subaverage IQs. Pediatrics 110;e34, 2002.

van Bellinghen $M$, de Troch C: Risperidone in the treatment of behavioral disturbances in children and adolescents with borderline intellectual functioning: A double-blind, placebo-controlled pilot trial. J Child Adolesc Psychopharmacology 11:5-13, 2001.

Wechsler D: Wechsler Intelligence Scale for Children-Revised. New York, The Psychological Corporation, 1974.

Address reprint requests to: Magali Reyes, M.D. Johnson E Johnson Pharmaceutical Research and Development 1125 Trenton-Harbourton Road Titusville, NJ 08530 E-mail: MHarde@prdus.jnj.com 